\title{
Stronger Together: Educational Service Augmenters and Traditional Predictors of Adjustment for International Students in the US
}

\author{
Cong Cong* and Chris R. Glass \\ Old Dominion University, United States \\ *Corresponding author: Email: summerccong@gmail.com \\ Address: 2309 Education Building, Old Dominion University, Norfolk, VA United States
}

\section{Introduction}

Higher education has been classified as a marketable service by the General Agreement on Trade Services by the World Trade Organization (Russell 2005). From the perspective of education as a marketable service, international students are viewed as consumers who expect high-quality services and outcomes, and universities are viewed as businesses selling a core product: educational services (Elsharnouby 2016). Higher education marketing researchers view international students as consumers who assess the quality of the educational services - the product - before purchase and consumption - acceptance and matriculation to a university (Paswan and Ganesh 2009). As higher education is shaped by neo-liberal economics forces, universities adapt marketing, recruiting, and branding practices from the business world to position themselves in a competitive global marketplace. To influence prospective students' perceptions of educational quality, universities engage in marketing campaigns that highlight campus life, academic services, and support services, that add value to the core degree programs offered at the university (Findlay, McCollum, and Packwood 2016).

In the marketing research literature, these supplemental services are referred to as educational service augmenters, defined as factors "outside of the domain of the core content of education that might emerge as crucial for determining students' satisfaction" (Elsharnouby 2016, 681). In the most-cited marketing research literature, educational service augmenters are intended to capture the elements of the university (e.g., academic advising, writing support services, immigration advising, etc.) that add value to the core service (i.e., degree programme), and thereby provide a competitive edge (Pawan and Ganesh 2009). Research suggests that supplemental services, in addition to the degree programme, play a crucial role in international students' evaluation of educational quality (Garrett 2014).

The consumer-centric language of the marketing research literature focuses on the private benefits of a university education, and language, such as educational service augmentation, marks a significant departure from traditional ways of framing and assessing educational quality (Marginson 2018). The neo-liberal ideology that treats international students as consumers is acute in a context where internationalization is scrutinized as a form of privatization, in which international students are valued for the substantial revenue they generate for host universities (Cantwell 2015; Deschamps and Lee 2015). Currently, marketing and higher education research remain far apart in terms of frameworks to understand the international student experience (Pawan, Spears and Ganesh 2007). The marketing research literature tends to examine educational quality in terms of customer experience and loyalty through satisfaction surveys, consumer-to-consumer recommendations, and brand reputation (Elsharnouby 2016). The higher education research literature, in contrast, traditionally examined educational quality in terms of academic outcomes through the direct and indirect assessment of students' knowledge and skills (Glass, Gómez, and Uzura 2014).

This study addresses a gap by connecting these two disparate literatures to analyze the relative strength of educational service augmenters along with traditional predictors in the academic and social adjustment of international students. We examined the extent to which educational service augmenters and traditional predictors are 
complementary, yet distinct, predictors of academic and social adjustment. Our main research question is: To what extent is there a difference in predicting international students' academic and social adjustment between students' satisfaction with educational service augmenters and traditional predictors? We focus on three service augmenters: educational support services, social support services, and campus support services, as well as three traditional predictors: language proficiency, friendships with US peers, and welcoming institutional attitude. We define adjustment as "a dynamic and interactive process that takes place between the person and the environment and is directed towards an achievement of the fit between the two" (Janjua, Malik, and Rahman 2011, 1360). A focus on both educational service augmenters and traditional predictors adds needed emphasis on the university's responsibility in international student adjustment.

\section{Core and Augmented Services in Higher Education}

Marketing researchers view students as consumers of educational services in the higher education market (Goralski and Tootoonchi 2015). Services in the higher education setting are classified into core level services and augmented level services (Elsharnouby 2016). The core level service of universities is education itself, including teaching quality and faculty expertise (Clemes, Ozanne, and Tram 2001). Augmented services include services such as academic support services, student support services, and campus life services (Clemes et al. 2001). In relation to the current study, studies in international student satisfaction have primarily focused on core service quality (Parahoo, Harvey, and Tamim 2013). However, augmented level services may have a strong relationship with academic and social adjustment. Parahoo et al. (2013) stated the concept of the student experience relates "not only to interactions with faculty, courses, and overall learning experiences, but also to other aspects that fall within the domain of student life such as administrative service, staff, physical characteristics of academic facilities, social environment, and advising support" (137-138).

\section{Education Augmenters as Predictors of Adjustment}

First, educational support services, such as writing centers, tutoring, and academic technology support, play a key role in the experiences of international students. Numerous studies cite the importance of academic writing support on international student satisfaction and adjustment (e.g. Curtin, Stewart, and Ostrove 2013; Trice and Yoo 2007). International students may keep problems to themselves or ask friends for advice if they consider academic support services to be inadequate. Moreover, international students often view their professors as potential sources of information and support to help them succeed academically (Curtin et al. 2013). Interaction with faculty members, inthe-classroom or during office hours, has been shown to predict students' positive educational experiences (Glass, Gesing, Hales, and Cong 2017; Kim and Sax 2009). Furthermore, "more contact between students and faculty, both inside and outside the classroom, enhances college students' development and learning outcomes" (Kim and Sax 2009, 438).

Second, social support services foster a "perception or experience that one is cared for, esteemed, and part of a mutually supportive social network" (Taylor 2011, 189). It has been shown that social support is essential when international students experience stress, particularly as it buffers against psychological distress (Glass and Westmont 2014). The number and quality of supportive relationships is strongly associated with positive adjustment (Tomkins, Brecht and Tucker 2016), and social support ensures international students succeed (Urban and Palmer 2016).

Third, campus support services offer administrative services, campus safety and security, financial aid advising, and maintenance services (Paswan, Spears, and Ganesh 2007). These basic services ensure international students are satisfied with the quality of the core product. For example, visa and immigration services ensure that all international 
students' study and work legally and are essential for "maintaining the exchange relationship in the context of international student-university interaction" (Paswan and Ganesh 2009, 81).

\section{Traditional Predictors of Adjustment}

Gallagher (2013) emphasized the important role of second language proficiency in the adaptation process, in that "the ability of communicating in a second language effectively is essential to "successful interfacing with the host culture" (52). Glass et al. (2014) found a positive relationship between second language proficiency and sociocultural adaptation; and research consistently shows that fluency in the host country's language is a significant variable affecting students' academic and social adjustment (Gallagher 2013; Kang 2006). Higher levels of language proficiency result in less adjustment stress and higher overall satisfaction (Sawir et al. 2012).

Numerous studies have shown that friendships with host country peers are among the most important factors influencing the social adjustment of international students (Gareis 2012; Rienties and Nolan 2014; C. Rose-Redwood and R. Rose-Redwood 2018). Friendships with host students provide security for international students to explore an unfamiliar cultural environment (Glass et al. 2013). Research indicates that "even 'weak ties' with host country students contributed to an international student's sense of social connectedness and well-being" (Gómez et al. 2014, 11). In sum, the addition of local students to international students' personal social networks facilitates their overall adjustment (Rienties and Nolan 2014).

Finally, a welcoming institutional attitude is one of the key factors that fosters sense of belonging (Stebleton, Soria, Huesman, and Torres 2014). A welcoming institutional attitude reflects whether international students perceive their institution values the international student population, as well as whether students have friends and make as many friends as they had hoped at their college or university (Redden 2014). Research demonstrates that a welcoming institutional attitude fosters a strong sense of belonging, which provides a more secure base for international students to explore the campus and local community (Glass and Westmont 2014). A welcoming campus environment facilitates international students' acculturation, understandably often focusing on the experiences of participating in a new culture (Gomez et al. 2014).

\section{Method}

Our study is based on an online survey, the International Student Satisfaction and Adjustment Inventory (ISSAI, $n=240$ ), developed for the purposes of this study. Items were developed based on a review of empirical research on the measurement of international student adjustment, as well as the marketing research literature on educational service augmenters . A pilot study was conducted to ensure the face validity of the items and the reliability of the scales ( $\alpha$ $=.80-.92$ ). The final instrument was sent to international students studying in the US through convenience sampling: they replied to an email from NAFSA: Association of International Educators with a survey link. A survey link was also posted on social media pages affiliated with international student affairs to gather more participants from various geographical locations. Table 1 reports the gender, level of study, years in US, and country of origin of participants, as well as descriptive statistics for all variables.

Table 1: Means and standard deviations for the variables used in the analysis

\begin{tabular}{llllll}
\hline Variable & Mean & SD & Min. & Max. & \multicolumn{1}{l}{} \\
\hline Educational service augmenters & 4.03 & .82 & 1.33 & 5.00 & 251 \\
Social support service augmenters & 3.62 & 1.02 & 1.00 & 5.00 & 250 \\
Campus support service augmenters & 4.02 & .83 & 1.00 & 5.00 & 250 \\
Academic and personal adjustment & 4.11 & .85 & 1.00 & 5.00 & 245
\end{tabular}




\begin{tabular}{|c|c|c|c|c|c|}
\hline Social adjustment & 3.70 & 1.02 & 1.00 & 5.00 & 245 \\
\hline Language Proficiency & 4.21 & .88 & 1.00 & 5.00 & 243 \\
\hline Friendships with American Peers & 3.50 & 1.12 & 1.00 & 5.00 & 243 \\
\hline Welcoming Institutional Attitude & 3.89 & 1.12 & 1.00 & 5.00 & 250 \\
\hline Variable & $\%$ & & Min. & Max. & $N$ \\
\hline Gender & & & 0 & 1 & 226 \\
\hline Female & 48.2 & & & & 105 \\
\hline Male & 51.8 & & & & 121 \\
\hline Level of Study & & & 1 & 4 & 240 \\
\hline Undergraduate - Bachelors & 37.2 & & & & 89 \\
\hline Graduate - Masters & 26.2 & & & & 63 \\
\hline Graduate $-\mathrm{PhD}$ & 30.8 & & & & 74 \\
\hline Other & 5.8 & & & & 14 \\
\hline Years in the US & & & 1 & 4 & 241 \\
\hline Less than 1 year & 29.5 & & & & 71 \\
\hline $1-3$ years & 46.1 & & & & 111 \\
\hline 4-5 years & 19.1 & & & & 46 \\
\hline 6 or more years & 5.4 & & & & 13 \\
\hline Country of origin & & & 1 & 3 & 244 \\
\hline China & 20.5 & & & & 50 \\
\hline India & 14.8 & & & & 36 \\
\hline Other countries & 64.7 & & & & 158 \\
\hline
\end{tabular}

The context of this study is a higher education service marketed to all international students who are currently enrolled in U.S higher education institutions. In 2016, the year this study was conducted, the total international student enrollment in the US had just crossed over one-million international students (Institute of International Education [IIE] 2016), and new international enrollment was at its peak prior to subsequent declines after the inauguration of President Trump. International students represent just over 5 percent of the overall enrollment at US higher education institutions, with China, India, South Korea, and Saudi Arabia as the leading places of origin.

Respondents rated their satisfaction with education service augmenters, social support augmenters, and campus support augmenters on a 5-point Likert scale, ranging from 1 (strongly disagree) to 5 (strongly agree). Educational service augmenters $(\alpha=.87)$ examined respondents' satisfaction with (1) the academic support provided by their program of study, (2) academic department, (3) professors, (4) university resources, (5) accessibility of professors outof-class, and (6) support from their academic advisor to reach their goals. For example, respondents rated their satisfaction with "the academic support provided by my program of study." Social support augmenters $(\alpha=.88)$ examined respondents' satisfaction with the (1) social activities available for international students, (2) opportunities for international students to network, and (3) guidance provided by the university to support involvement in campus social activities. For example, respondents rated their satisfaction with "the social activities available on campus for international students." Campus support service augmenters $(\alpha=.87)$ examined respondents' satisfaction with the (1) campus immigration office services, (2) campus infrastructure, (3) campus environment, (4) responsiveness of services to individual students, and (5) overall service-orientation towards international students. For example, respondents rated their satisfaction with "the Campus Immigration Office services if I ever need them." 
Traditional predictors included English language proficiency, friendships with US peers, and welcoming institutional attitudes towards international students. First, respondents indicated their English language proficiency as beginner, early intermediate, intermediate, early advanced, or advanced. Second, they indicated whether (1) they were satisfied with their friendship with American peers and (2) easily become friends with American peers on a 5-point Likert scale, ranging from 1 (strongly disagree) to 5 (strongly agree) $(\alpha=.87)$. Third, they rated the extent to which they believed their college or university values international students on a 5-point Likert scale, ranging from 1 (strongly disagree) to 5 (strongly agree). In addition, we include several control variables in our models, namely gender (male, female); level of study (bachelors, masters, doctoral, and other); years in host country (less than a year, 1-3 years, 4-5 years, 6 or more years); and country of origin (China, India, and other countries).

The final section measured academic and social adjustment. For academic adjustment respondents indicated (1) if they enjoyed their courses, (2) fit into their academic program, (3) fit in with classmates, and (4) were pleased with their decision to attend their college or university on a 5-point Likert scale, ranging from 1 (strongly disagree) to 5 (strongly agree) ( $\alpha=$.86). Participants responded to items such as, "I feel that I am enjoying most of my courses." For social adjustment respondents indicated on a 5-point Likert scale, ranging from 1 (strongly disagree) to 5 (strongly agree) $(\alpha=.79)$ if they felt like they (1) belonged at their college or university, (2) had close and supportive relationships, and (3) could interact with as many people as they desired to at their college or university. Participants responded to items such as, "I feel that I belong at this college/university."

Hierarchical multiple regression was used to examine the relationship between educational service augmenters, traditional predictors of adjustment, and academic and social adjustment. Correlations between factors (.41 - .65) and Variance Inflation Factor (VIF) values (1.01 - 3.07) were moderate which suggest the factors are related, but distinctly defined. Hierarchical multiple regression was chosen to examine if service augmentation variables of interest explained a statistically significant amount of variance in academic and social adjustment after accounting for traditional predictors.

\section{Results}

The first hierarchical multiple regression analysis aimed to determine if international students' satisfaction with educational service augmenters is related to academic adjustment after controlling the traditional predictors (see Table 2). The regression of the three traditional predictors on academic adjustment explained $30 \%$ of the variance in international students' academic adjustment; $F(3,237)=34.80$, MSE $=17.57, p<.001$. Welcoming institutional attitude $(\beta=.31 p<.001)$, friendships with host country peers $(\beta=.24 p<.001)$, and language proficiency $(\beta=.16 p$ $=.006)$ had a positive relationship with academic adjustment. The addition of service augmenters in model 2 explained $68 \%$ of the total variance in international students' academic adjustment, $F(6,234)=87.45$, MSE $=19.87, p<.001$ and led to a significant change in $R^{2}\left(\Delta R^{2}=.38, p<.001\right)$, explaining an additional $38 \%$ of variance. Educational service augmenters $(\beta=.60, p<.001)$ and campus support service augmenters $(\beta=.21, p=.001)$ were significantly related to academic adjustment, as well as language proficiency $(\beta=.13, p=.002)$ and friendships with host country peers $(\beta=.12, p=.010)$. These relationships persisted in the full model (model 3), $F(15,225)=36.40, \mathrm{MSE}=8.14, \mathrm{p}$ $<.001$, with none of the demographic control variables significantly related to academic adjustment.

Table 2: Predictors of international graduate students' academic adjustment, hierarchical multiple regression

Model I Model II Model III

\section{Traditional Predictors}

Language Proficiency

Friendships
$0.16(.06)^{* *}$
$0.13(.04)^{* * *}$
$0.10(.04)^{*}$
$0.24(.05)^{* * *}$
$0.12(.04)^{* * *}$
$0.13(.04)^{* *}$ 
Welcoming Institutional Attitude

$$
0.31(.05)^{* * *} \quad 0.03(.04)
$$

$0.05(.04)$

Education Service Augmenters

Educational Support Augmenters

Social Support Augmenters

Campus Support Augmenters

$$
\begin{array}{ll}
0.60(.05)^{* * *} & 0.61(.05)^{* * *} \\
-0.04(.04) & -0.06(.04) \\
0.21(.06)^{* * *} & 0.19(.07)^{* *}
\end{array}
$$

\section{Control variables}

Years in US (ref: Less than 1 year)

$$
1-3 \text { years }
$$

$0.06(.07)$

4-5 years

$0.01(.09)$

6 or more years

$0.02(.21)$

Gender (ref: Male)

$0.02(.06)$

Level of study (ref: Undergraduate)

Masters

$0.06(.08)$

$\mathrm{PhD}$

Other

\section{Country (ref: China)}

India

Other countries

\begin{tabular}{llll}
$\mathrm{R}^{2}$ & $.31 * * *$ & $.69 * * *$ & $.71 * * *$ \\
$N$ & 240 & 240 & 240 \\
\hline
\end{tabular}

Notes: Reported values are unstandardized coefficients with standard errors between parentheses.

$* p<.05, * * p<.01, * * * p<.001$

The second hierarchical multiple regression analysis was conducted to determine if international students' satisfaction with educational service augmenters is related to social adjustment after controlling the traditional predictors (see Table 3). A regression of the three traditional predictors on social adjustment explained $42 \%$ of the variance in international students' social adjustment; $F(3,237)=56.11, \mathrm{MS}=34.48, p<.001$ (model 1). Friendships with host country peers $(\beta=.56, p<.001)$ and a welcoming institutional attitude $(\beta=.17, p=.004)$ had a positive relationship with social adjustment. The addition of service augmenters explained $54 \%$ of the total variance in international students' social adjustment, $F(6,234)=45.80$, MSE $=22.42$, and led to a small but significant change in $R^{2}\left(\Delta R^{2}=.12, p<.001\right)$, explaining an additional $12 \%$ of the variance in international students' social adjustment (model 2). Educational support service augmenters $(\beta=.21, p<.001)$ and campus support service augmenters $(\beta=.19$, $p=.010)$, as well as friendships with host country peers $(\beta=.47, p<.001)$ were significantly related to social adjustment. These relationships persisted in the full model (model 3) where control variables were added, $F(15,225)=$ $19.85, \mathrm{MSE}=9.46, \mathrm{p}<.001$. Gender had a small but significant relationship to social adjustment $(\beta=-.10, p=.035)$; and number of years in host country also had a small but significant relationship to social adjustment for one-to-three years in host country $(\beta=0.10, p=.043)$ and six or more years in host country $(\beta=0.09, p=.048)$. 
Table 3: Predictors of international graduate students' social adjustment, hierarchical multiple regression

\begin{tabular}{llll} 
& Model I & Model II & Model III \\
\hline Traditional Predictors & & & \\
Language Proficiency & $-0.07(.06)$ & $-0.06(.06)$ & $-0.07(.06)$ \\
Friendships & $0.56(.06)^{* * *}$ & $0.47(.05)^{* * * *}$ & $0.47(.05)^{* * *}$ \\
Welcoming Institutional Attitude & $0.17(.05)^{* *}$ & $-0.06(.06)$ & $-0.02(.06)$
\end{tabular}

Education Service Augmenters

Educational Support Augmenters

$0.21(.07)^{* * *} \quad 0.27(.08)^{* * * *}$

Social Support Augmenters

$0.13(.06)^{*} \quad 0.12(.06)$

Campus Support Augmenters

$0.19(.09)^{* *} \quad 0.13(.09)$

\section{Control variables}

Years in US (ref: Less than 1 year)

$\begin{array}{ll}1-3 \text { years } & 0.10(.10)^{*} \\ 4-5 \text { years } & 0.04(.13) \\ 6 \text { or more years } & 0.09(.30)^{*}\end{array}$

$\begin{array}{ll}\text { Gender (ref: Male) } & -0.10(.09)^{*}\end{array}$

Level of study (ref: Undergraduate)

Masters

$0.10(.12)$

$\mathrm{PhD}$

Other

$-0.02(.21)$

Country (ref: China)

India

$0.09(.18)$

Other countries

$-0.06(.13)$

$\begin{array}{llll}\mathrm{R}^{2} & .42 * * * & .54 * * * & .57 * * * \\ N & 240 & 240 & 240\end{array}$

Notes: Reported values are unstandardized coefficients with standard errors between parentheses.

$* p<.05, * * p<.01, * * * p<.001$

\section{Discussion}

This study aimed to contribute to research by bridging marketing and higher education research to understand international student adjustment (Pawan, Spears and Ganesh 2007). This focus is especially important as universities highlight how campus life, academic services, and support services add value to the core degree programs offered at the university. The results indicate the critical role of educational service augmenters, in addition to traditional predictors of adjustment in international students' adjustment. Educational service augmenters (i.e., academic advising, writing support services, immigration advising, etc.) explained an additional 38\% of variance in international students' 
academic adjustment; and $12 \%$ of variance in social adjustment. Rather than considering whether the traditional predictors or the educational service augmenters are better predictors of adjustment, the results indicate that they are complementary, yet distinct, predictors of academic and social adjustment. The results emphasize an organization's responsibility in international student integration into local communities and the importance of educational augmenters, especially with regard to international students' academic adjustment.

The results of this study support previous research that traditional predictors boost international students' adjustment (Hendrickson et al. 2011). They indicate that educational support augmenters and campus support augmenters are especially important for academic adjustment. As expected from previous research, among all regression analyses, friendships with US peers is most strongly correlated with adjustment (Gareis 2012), before and after adding educational service augmenters into the model, and English proficiency significantly correlates with international students' academic adjustment.

The additional amount of variance explained by educational augmenters supports previous research on the importance of faculty members for academic adjustment (Glass et al. 2017), as well as educational support services and campus support services for academic adjustment (Kim and Sax 2009). Professors engage students' interest in pursuing an academic degree and provide advice that helps students succeed (Curtin et al. 2013). Faculty, indeed, have "a critical role in designing and delivering learning opportunities. As the institutional agents who instruct, advice, and mentor students in classes and courses, academic programs, and co-curricular activities, faculty members are a dominant force in shaping students' learning experience and learning outcomes. Student engagement begins with faculty engagement" (Chen et al. 2008, 341).

This study has a number of limitations. It is important to recognize that not all international students experience university in the same way and place-based factors are essential to social and academic adjustment, e.g. city size, diversity, etc. Our convenience sample relied on a relatively small sample size, so it is difficult to make strong inferences to the overall international students population in the US. Future research could use a larger sample of international students and include place-based factors as control variables that influence academic and social adjustment, in addition to the traditional predictors and educational service augmenters used in the current study. In addition, the study focuses on the private benefits of higher education for individual international students. Further research should use case study research to explore higher education as a global public good where international students cross-border study contributes to non-excludability benefits made broadly available across populations on a global scale (Marginson 2018). Researchers used a non-probability convenience sampling strategy, so there is no way to assess sampling bias, limiting the generalizability of the results. Finally, the applicability of this research outside the US is limited due to the relatively large and extensive number of student support staff and services offered at US universities compared with how similar services are organized and staffed at universities outside the US.

\section{Implications}

The present study indicates that there are statistically significant relationships between satisfaction with educational service augmenters and international students' adjustment. We propose three recommendations for practice. First, academic departments and programs should focus on facilitating positive faculty-student relationships. The more international students are satisfied with faculty support and fit within their department and programs, the more they consider themselves well-adjusted to their university life. As academic achievement and social adjustment are higher among peer-mentored international students than among non-peer-mentored international students, higher education institutions must place more emphasis on connecting international students with US peers to facilitate intercultural friendship formation. Student service units that provide co-curricular programming are essential education service augmenters. Peer-mentoring programs, as mentioned above, are the best known of these. Such programs 
provide an excellent means of enhancing intercultural connection and integration, and link to more positive attitudes of US students towards international students.

\section{References}

Cantwell, Brendan. "Are international students cash cows? Examining the relationship between new international undergraduate enrollments and institutional revenue at public colleges and universities in the U.S." Journal of International Students 5 (2015): 512-525.

Chen, Helen L., Lisa R. Lattuca, and Eric R. Hamilton. "Conceptualizing engagement: Contributions of faculty to student engagement in engineering." Journal of Engineering Education 97 (2008): 339-353.

Clemes, Michael D., Lucie K. Ozanne, and Lam Tram. "An examination of students' perceptions of service quality in higher education." Journal of Marketing for Higher Education 10 (2001): 1-20.

Curtin, Nicola, Abigail J. Stewart, and Joan M. Ostrove. "Fostering academic self-concept advisor support and sense of belonging among international and domestic graduate students." American Educational Research Journal 50 (2013): 108-137.

Deschamps, Eric, and Jenny J. Lee, 'Internationalization as mergers and acquisitions: Senior International Officers' entrepreneurial strategies and activities in public universities. Journal of Studies in International Education 19 (2015): 1-18. doi.org/10.1177/1028315314538284

Elsharnouby, Tamer H. "Participation behavior among international students: the role of satisfaction with service augmentation and brand choice attainment." International Journal of Educational Management 30 (2016): 679697.

Findlay, Allan M., David McCollum, and Helen Packwood. "Marketization, marketing and the production of international student migration." International Migration 55.3 (2017): 139-155.

Gareis, Elisabeth. "Intercultural friendship: Effects of home and host region." Journal of International and Intercultural Communication 5 (2012): 309-328.

Garrett, Richard. "Explaining international student satisfaction: Insights from the international student barometer." Retrieved August 27 (2014).

Gallagher, H. Colin. "Willingness to communicate and cross-cultural adaptation: L2 communication and acculturative stress as transaction." Applied Linguistics 34 (2013): 53-73.

Glass, Chris R., Stephanie Buus, and Larry A. Braskamp. Uneven experiences: What's missing and what matters for today's international students. Chicago, IL: Global Perspective Institute, 2013.

Glass, Chris R., Peggy Gesing, Angela Hales, and Cong Cong. "Faculty as bridges to co-curricular engagement and community for first-generation international students." Studies in Higher Education 42 (2017): 895-910.

Glass, Chris R., Edwin Gómez, and Alfredo Urzua. "Recreation, intercultural friendship, and international students' adaptation to college by region of origin." International Journal of Intercultural Relations 42 (2014): 104-117.

Glass, Chris R., and Christina M. Westmont. "Comparative effects of belongingness on the academic success and cross-cultural interactions of domestic and international students." International Journal of Intercultural Relations 38 (2014): 106-119.

Gomez, Edwin, Alfredo Urzua, and Chris R. Glass. "International student adjustment to college: Social networks, acculturation and leisure." Journal of Park and Recreation Administration 32 (2014): 7-25.

Goralski, Margaret A., and Ahmad Tootoonchi. "Recruitment of International Students to the United States: Implications for Institutions of Higher Education." International Journal of Education Research 10 (2015): 53-66.

Hendrickson, Blake, Devan Rosen, and R. Kelly Aune. "An analysis of friendship networks, social connectedness, homesickness, and satisfaction levels of international students." International Journal of Intercultural Relations 35 (2011): 281-295. 
Janjua, Fouzia, Samina Malik, and Fazalur Rahman. "Learning experiences and academic adjustment of international students: A case study from Pakistan." Journal of Language Teaching and Research 2 (2011): 1359-1365.

Kang, Sun-Mee. "Measurement of acculturation, scale formats, and language competence: Their implications for adjustment." Journal of Cross-Cultural Psychology 37(2006): 669- 693.

Kim, Young K., and Linda J. Sax. "Student-faculty interaction in research universities: Differences by student gender, race, social class, and first-generation status." Research in Higher Education 50 (2009): 437-459.

Marginson, Simon. 2018. "The New Geo-Politics of Higher Education: Global Cooperation, National Competition and Social Inequality in the World-Class University (WCU) Sector." Centre for Global Development, Working Paper 34.

Parahoo, Sanjai K., Heather L. Harvey, and Rana M. Tamim. "Factors influencing student satisfaction in universities in the Gulf region: does gender of students matter? Journal of Marketing for Higher Education, 23(2), 135-154." (2013): 135-154.

Paswan, Audhesh K., and Gopala Ganesh. "Higher education institutions: satisfaction and loyalty among international students." Journal of Marketing for Higher Education 19 (2009): 65-84.

Paswan, Audhesh K., Nancy Spears, and Gopala Ganesh. "The effects of obtaining one's preferred service brand on consumer satisfaction and brand loyalty." Journal of Services Marketing 21 (2007): 75-87.

Parameswaran, Ravi and Aleksandra E. Glowacka. "University image: an information processing perspective." Journal of Marketing for Higher Education 6 (1995): 41-56.

Redden, Elizabeth. "The international-friendly campus." InsideHigherEd (2014). https://www.insidehighered.com/ news/2014/05/30/international-educators-discuss-ways-make-campus-more-international-student-friendly (retrieved October 5, 2018).

Rienties, Bart, and Eimear-Marie Nolan. "Understanding friendship and learning networks of international and host students using longitudinal Social Network Analysis." International Journal of Intercultural Relations 41 (2014): 165-180.

Rose-Redwood, CindyAnn, and Reuben Rose-Redwood. "Building Bridges Across the International Divide: Fostering Meaningful Cross-Cultural Interactions Between Domestic and International Students." Journal of International Students 8.3 (2018): 1328-1336.

Russell, Marilyn. "Marketing education: A review of service quality perceptions among international students." International Journal of Contemporary Hospitality Management 17 (2005): 65-77.

Rundles, Kyle. "Factors impacting the psychological adjustment of Saudi Arabian international students in the United States: Self-esteem, social support, and discrimination (Doctoral dissertation, The Chicago School of Professional Psychology)." (2013).

Sawir, Erlenawati, Simon Marginson, Helen Forbes-Mewett, Chris Nyland, and Gaby Ramia. "International student security and English language proficiency." Journal of Studies in International Education 16 (2012): 434-454.

Stebleton, Michael J., Krista M. Soria, Ronald L. Huesman Jr, and Vasti Torres. "Recent immigrant students at research universities: The relationship between campus climate and sense of belonging." Journal of College Student Development 55 (2014): 196-202.

Taylor, Shelley E. Social support: A review (pp. 192-217). In H.S. Friedman (Ed.), Oxford Handbook of Health Psychology. New York, NY: Oxford University Press, 2011.

Tompkins, Kelley A., Kierra Brecht, Brock Tucker, Lucia L. Neander, and Joshua K. Swift. "Who matters most? The contribution of faculty, student-peers, and outside support in predicting graduate student satisfaction." Training and Education in Professional Psychology 10 (2016): 102-108.

Trice, Andrea G., and Jin Eun Yoo. "International graduate students' perceptions of their academic experience." Journal of Research in International Education 6 (2007): 41-66. 
Urban, Ewa, and Louann Bierlein Palmer. " International Students' Perceptions of the Value of US Higher Education." Journal of International Students 6 (2016): 153-174. 